UNIVERSITY OF CHITRAL JOURNAL OF LINGUISTICS AND LITERATURE

VOL. 5 | ISSUE II | JULY - DEC | 2021

ISSN (E): 2663-1512, ISSN (P): 2617-3611

https://doi.org/10.33195/j1l.v5iII.297

\title{
NATIVISATION AND VARIATION OF DISCOURSE MARKERS IN PAKISTANI ENGLISH
}

Mehwish Noor

PhD Scholar (English) Department of English, Faculty of Arts, University of Gujrat, Pakistan noorlinguist@gmail.com

Behzad Anwar

Assistant Professor, Department of English Faculty of Arts, University of Gujrat, Gujrat, Pakistan behzad.anwar@uog.edu.pk

\begin{abstract}
This study aims at analyzing nativisation, variation and categorization of Discourse markers in Pakistani English by the application of Fraser (1999) taxonomy of discourse markers. The data is drawn and analysed manually. Two corpora: BNC and PENC are used for identifying nativisation and variation. First 100 occurrences of BNC are taken into consideration for the study of functions and positions of discourse makers. Data is shown in tables and is further discussed in detail. There are twelve nativised DMs and ten variant DMs found whereas, variation in position of six DMs is analysed. The study supports the notion of negotiating the context-based meaning through DMs and reinforces the multiplicity of functioning of DMs presented by Schiffrin (1987) and Müller (2005). It responses to the claim of transparent DM made by Ariel (1994) and illustrates its multiple functions. Furthermore, it posits a contrast to the study of Lahuerta (2004) that places of course into inferential category of DMs by highlighting its dual functionality in PE performing the functions of elaborative and inferential DM. Moreover, it adds the analysis of combination of inferential and elaborative DMs ignored by Fraser (2015). This pioneering work studies DMs in written discourse (Pakistani English novels) and offers a foundational ground to the research of non-native varieties of English.
\end{abstract}

Keywords: Pakistani English; Non-native variety; Nativisation; Variation; Discourse Markers (DMs); Fraser Taxonomy

\section{INTRODUCTION}

The English language, due to globalization, is no more a commodity of natives now a day; rather it is owned and welcomed by non-natives who are in majority than the native speakers of English (Llurda, 2004). This phenomenon leads to variation and language change in lieu of multilingual contexts in which English is being used. In the sphere of World Englishes, Pakistani English is on the way towards its independent status. It requires linguistic research from different dimensions, aspects, and perspectives. For the purpose, the current study intends to highlight, categorize, and analyze discourse markers. 
UNIVERSITY OF CHITRAL JOURNAL OF LINGUISTICS AND LITERATURE

VOL. 5 | ISSUE II | JULY - DEC | 2021

ISSN (E): 2663-1512, ISSN (P): 2617-3611

https://doi.org/10.33195/j1l.v5iII.297

Discourse markers are differently defined and termed by various scholars. They are termed as; discourse cues, discourse connectives, discourse particles, phatic connectives, semantic conjuncts, pragmatic markers, discourse operators, discourse signaling devices, pragmatic expressions, pragmatic formatives, and sentence connectives (Fraser, 1999). Defining them is as controversial as their nomenclature (ibid). They might be words or phrases, or clauses of comments, conjunctions, adverbials, and interjections used to catch the attention of the listener towards forth-coming utterance within the direct context of discourse (Redeker, 1991). They provide coherence and cohesion to discourse whether short or large in length. They exceed the grammatical structure of discourse (Feng, 2010) as discourse is not simply an arrangement of different length of clauses and sentences. For assigning meaning and making a link among isolated sentences, discourse markers play their defining role. For Halliday and Hassan (1976), their presence is presupposed to offer connectedness and cohesion to discourse. Similarly, Schiffrin (1987) views them as functional devices which arrange context-based coordination during continuing talk. This is to say, they are components, successively dependent, which strut piece of talk.

Discourse markers perform various functions, and one discourse marker may perform multiple functions with reference to its use within different contexts. Their categorization is also complex in nature since they may fall into more than one functional category (Guo, 2015). They lubricate and support continuity of discourse (Crystal, 2012). They also link the segments of text; facilitate turn taking and topic change. They also account for the delay strategy and speech repairing processes. They are also used for showing solidarity and reinforce shared knowledge of the interlocutors (Fung and Carter, 2007). Kammensjo (2005) point outs that DMs act as indicators for the interpretative inferences and restrict the other options for interpretations. For investigating the appropriate use of DMs and pedagogical insinuations, research is suggested to improve the learning skills (Sharndama and Yakubu, 2013).

It is observed that the study of discourse markers which is an important part of linguistic as well as pragmatic competence of language is not adequately addressed in Pakistani English. Though a study by Jabeen et al (2011) finds its way to analyze them yet there is a research gap since it is strictly related to corpus-based investigation. They focused on discourse markers 
UNIVERSITY OF CHITRAL JOURNAL OF LINGUISTICS AND LITERATURE

VOL. 5 | ISSUE II | JULY - DEC | 2021

https://doi.org/10.33195/j1l.v5iII.297

and restricted themselves to spoken discourse. The study enlarges the foci to written text and finds out variant forms and use of discourse markers. For the purpose, following are the objectives of the present research.

\subsection{Statement of Problem}

Pakistani English is a new English variety in the sphere of English-speaking world. Though it was identified by Kachru (1983) as a variety of South Asian English, yet it lacks in codification and standardization. It is observed that the study of discourse markers, which is an important part of linguistic as well as pragmatic competence of language, is not adequately addressed in Pakistani English particularly in written text.

\subsection{Hypothesis}

Variation and nativisation of discourse markers exist in Pakistani English.

\subsection{Research Objectives}

The study aims:

i) To find out nativised DMs

ii) To find out variation according to their usage

iii)To categorize them according to their functions

The following section mentions the questions that the study intends to get the answers.

\subsection{Research Questions}

i. What are the nativised occurrences of DMs in PE?

ii. What are the various functions performed by DMs in PE as compared to the Standard English?

iii. What are the different categories of DMs in PE?

\section{REVIEW OF LITERATURE}

The study of discourse marker is considered as, "a growing market in the sphere of linguistics" (Fraser, 1998). Castro (2009) opines that discourse markers perform various interpersonal and text-based functions to allot coherence and contextual flow to discourse. The study focus is limited to classroom interaction, yet non-native context is of the interest of the current study. The study highlights the significant role of discourse markers for the appropriate use of language. The study focuses on verbal discourse whereas; the present study concentrates on written discourse which is neglected by much of the available literature. 
UNIVERSITY OF CHITRAL JOURNAL OF LINGUISTICS AND LITERATURE

VOL. 5 | ISSUE II | JULY - DEC | 2021

ISSN (E): 2663-1512, ISSN (P): 2617-3611

https://doi.org/10.33195/j1l.v5iII.297

Fuller (2003) examines the use of well, oh and you know with reference to the relationship between the interlocutors and finds their functions as universal. Universality of their functions needs further investigation with reference to different language and context, but the basic tenant of my research is figuring out variation that is opposite to the universality claim.

The study of Gholami et al (2012), though, emphasizes on the analysis of discourse markers (DMs) with reference to written discourse; of scientific articles' abstracts in lieu of ESP published in journals yet their study is quantitative in nature and restricts to the comparative analysis percentage of functional and lexical words.

Hauge (2014) studies the translation of a text where the source text does not have discourse markers, but translator uses them while translating it into target language. This study puts forth the assumption of the present researcher that every language has its own DMs and their collection in lexicon vary with reference to different languages. The present researcher is of the opinion that though Pakistani English (PE) is a variety of Standard British English (SBE) yet it has distinctive use of DMs and carries some nativised DMs as well. Furthermore, Hauge (2014) opines that DMs have functions but lack semantic value and do not affect the propositional value of the sentence in which they are used. Hansen (2006) is of the similar opinion and propounds that they are not meta-discursive components. The current researcher partially agrees with the notion and believes that they are not totally meaningless elements of discourse rather their functions are related to their literal meanings to which they are homophonous (e.g. conjunctions and interjections).

Kalajahi (2012) examines DMs in both: written and spoken discourse with reference to pupils' attitude and claims that they offer a proper direction to the listeners/readers, facilitate the comprehension of meaning, provide sheer understanding of discourse context, and show that how better listener/reader can understand the speaker/writer. This postulation supports the notion of the current researcher that DMs are not entirely meaning free elements rather they indicate as well as facilitate understanding of the sentences to which they are attached.

An influential study by Guo (2015) presents a disagreement of consensus and complexities exist among the theorists and scholars regarding the study of DMs. It offers an 
UNIVERSITY OF CHITRAL JOURNAL OF LINGUISTICS AND LITERATURE

VOL. 5 | ISSUE II | JULY - DEC | 2021

ISSN (E): 2663-1512, ISSN (P): 2617-3611

https://doi.org/10.33195/j1l.v5iII.297

overview of different studies with their various approaches, such as, structural, and functional etc. It cites the manifestation of Tree and Schrock (2002) in which they prove a correspondence between the literal meaning and functional meaning of DMs. It strengthens the present researcher's notion of semantic property of DMs related to their context-bound meaning.

Fung and Carter's (2007) study brings forth difference in the usage of DMs by native and non-native English learners and propounds that a wide range of functional categories of DMs are used by the natives while referential DMs are more likely used by the non-natives. The present study restricts itself to the non-native variety of English and interested in the nativised DMs (Yang, 2011).

Several studies regarding DMs are dedicated to English language teaching to teach their appropriate use for coherent and cohesive discourse competence to non-native leaners of English (Trillo, 2002; Feng, 2010). The study of Kaveifard and Allami (2011) emphasizes on DMs use by native English, native Persian and non-native Persian students and finds out results quantitatively. They applied the taxonomy of Fraser (1998) for their analysis. The current study inclines towards the same approach for the categorization of DMs. Hussein (2007) examines the two basic approaches towards theoretical underpinnings pertaining to the study of DMs: Coherence approach and Relevance Approach and prefers the account of Relevance rather than Coherence. The current researcher, conversely, values the former account over the later. It is so because it is completely generalized pragmatic approach towards DMs.

Valentine (1991) states that discourse and pragmatic perspectives of non-native varieties are less examined areas and need to be studied for a complete description of New Englishes. The study pertains to Indian English (IE) and elaborates DMs specific to Indian English and some others which perform functions different from the Standard English. Some of the data used by the researcher is gathered from bilingual speakers in code-switched form which might be questioned because the author claims the distinctiveness of the use of DMs with reference to IE. Anyhow, the present study also intends to highlight nativized DMs particularly and their distinctive functions generally. Siddique et al (2017) analyze metadiscourse in newspapers' editorials of Pakistan's English and devised a theoretical model to accommodate meta-discourse analysis. It seems influential but covers meta-discourse. 
UNIVERSITY OF CHITRAL JOURNAL OF LINGUISTICS AND LITERATURE

VOL. 5 | ISSUE II | JULY - DEC | 2021

ISSN (E): 2663-1512, ISSN (P): 2617-3611

https://doi.org/10.33195/j1l.v5iII.297

Jabeen et al (2011) study is the only available attempt to analyze DMs with reference to variation in use, but its focus of interest is totally restricted to eight DMs. Furthermore, the quantitative study highlights the frequency of DMs' use in PE and British English and finds out high frequency usage by the natives and low frequency of use by the PE speakers. They also figure out the position and location of DMs as, initial, middle and at the end of sentences. Although it opens a door to this perspective yet there lies research niche regarding enlisting and analyzing the nativised DMs specifically, pertaining to PE. Similarly, to validate the claim of variation and nativisation, only spoken data is not good enough and requires evidence from literary discourse which targets not only PE readership but also the international readership. Moreover, the mentioned study does not follow any taxonomic framework to categorize the DMs under study and assigns them functions according to their selected occurrences.

The present study applies Fraser's Taxonomy for the analysis and categorization of DMs. It is applied and suggested by the researchers for the analysis of written discourse. The next section discusses the theoretical and methodological strategies to answer the research questions.

\section{THEORETICAL FRAMEWORK}

As mentioned earlier, there are two schools of thought regarding DMs study; Coherence and Relevance and the present study takes the former for the data analysis with respect to classification based on Fraser's framework (1999) which is in the line of Schiffrin's (1987) pioneering work. According to Fraser (1996), the sentence' meaning is contingent to two contents, namely, propositional and non-propositional and the latter is pertinent to DMs.

It does not exclude the semantic property of DMs altogether rather consider them signaling four types of messages; basic, parallel, commentary and discourse messages and classifies DMs into two major types. They are function based; first are those DMs which pertain to the messages and the second which pertain to topics. The former consists of further sub-categories; collateral markers (I mean, and, also etc), inferential markers (then, thus, so etc.), additional markers (because, after all, since etc) and contrastive markers (contrary, but, though etc.) (Yang, 2011). 
UNIVERSITY OF CHITRAL JOURNAL OF LINGUISTICS AND LITERATURE

VOL. 5 | ISSUE II | JULY - DEC | 2021

https://doi.org/10.33195/j1l.v5iII.297

Figure-01: Types of Pragmatic Markers by Fraser (1999)

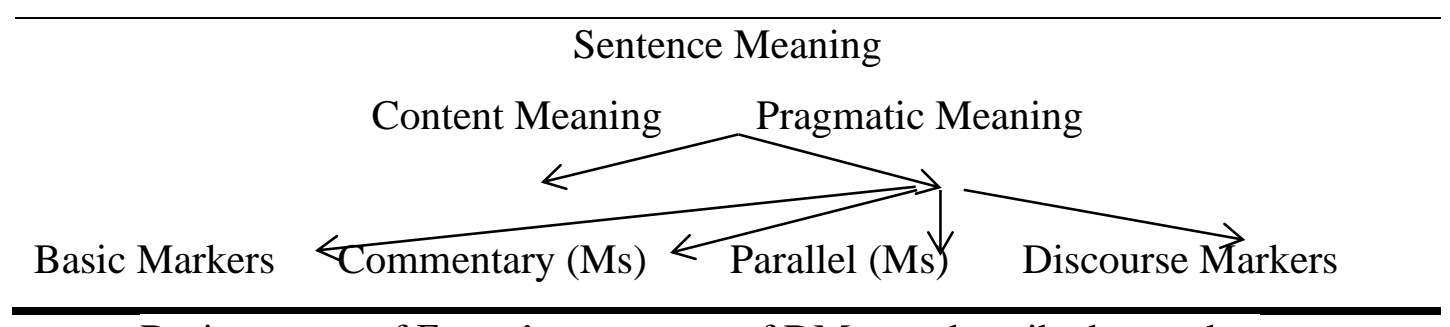

Basic tenants of Fraser's taxonomy of DMs are described as under.

- $\quad$ DMs have core meaning which is specifically negotiated by the context.

- They signal interpretational relationship between the segments they acquaint with, S2 and the previous segment $\mathrm{S} 1$.

This different kind of meaning is said to be, procedural which negotiate its interpretation by linguistic as well as conceptual contexts (Fraser, 1999). Furthermore, DMs not only link interpretational meaning between immediate segments; S1 and S2 but also acquaint with segments present previous in discourse, to which he calls global coherence. In this way, DMs provide directions to the listener/reader to interpret discourse segment they are attached to (ibid).

Fraser's taxonomy (1999) presents four main semantic relationships revealed to their use. They are illustrated in Figure-02.

\section{Figure-02: Fraser Taxonomy of Discourse Markers (1999)}

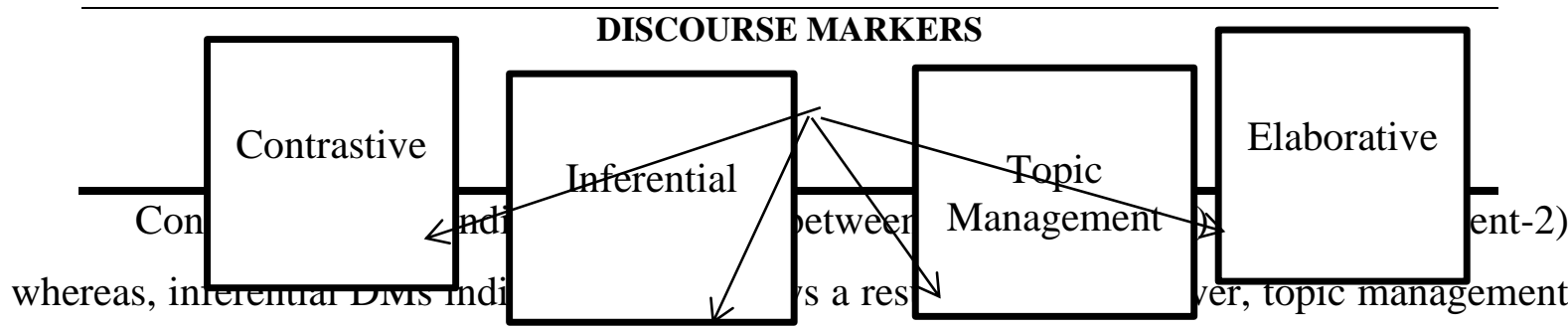

DMs high point a relation between S1 and S2 and elaborative DMs relate the features of S2 to S1 in a quasi-parallel fashion.

The current study takes the above-mentioned typology into account for the functionbased categorization of DMs (Jalilfar, 2008, Ali and Mahadin, 2016). The methodology and procedure of the study are discussed as under.

\section{METHODOLOGY}


UNIVERSITY OF CHITRAL JOURNAL OF LINGUISTICS AND LITERATURE

VOL. 5 | ISSUE II | JULY - DEC | 2021

ISSN (E): 2663-1512, ISSN (P): 2617-3611

https://doi.org/10.33195/j1l.v5iII.297

Research questions of the present study demand a blend of qualitative and quantitative research methods. To figure out nativized DMs (non-native variety specific), particularly and commonly used DMs in English a corpus of Pakistani English Novels (PENC) is used containing twenty-seven novel files with approximately 23million (2389767) words. British National Corpus (BNC) consists of 100 million words, is used to validate variation in the use and functions of selected DMs from PENC. Different functions and positions of the selected DMs are analysed manually and qualitatively. First 100 entries from BNC are analysed manually. The given frequency shows the collective occurrences of the entries out of which their use as DMs is analysed qualitatively. The supportive excerpts from PENC are listed in appendix. The respective DMs are given in bold for the ease of the reader. Furthermore, selected DMs of PE are categorized according to the Fraser (1999) typology. Though, corpora are used in the study, yet frequency of the occurrences is not strictly required. The data is shown in tabular form and further analysed qualitatively. The qualitative part of the discussion is descriptive in nature. The next section presents the result and analysis of the data.

\section{RESULTS AND DATA ANALYSIS}

This section provides the answers to research questions. The results are discussed according to the said questions. First, nativised DMs are searched from PENC and then matched through BNC. The below sub-section discusses nativised DMs.

\subsection{Nativized Discourse Markers}

The researcher finds out some culture specific DMs in response to the primary research question of the present study. They are used by PE fiction writers in order to employ coherence to their written discourse. It is worth noting that beside the fact that DMs are mostly used in spoken discourse and most of the previous studies on DMs are pertinent to spoken discourse, the present study highlights several nativised DMs from a small sized corpus of PE novels. The use of the selected DMs within sentences is given in the appendix. The Table-01 provides an overview of twelve DMs.

Table-01: Nativised DMs 
UNIVERSITY OF CHITRAL JOURNAL OF LINGUISTICS AND LITERATURE

VOL. 5 | ISSUE II | JULY - DEC | 2021

ISSN (E): 2663-1512, ISSN (P): 2617-3611

https://doi.org/10.33195/j1l.v5iII.297

\begin{tabular}{cllll}
\hline $\mathbf{1}$ & hai hai & Topic management & hai hai & not found \\
\hline $\mathbf{2}$ & Toba/tobatoba & Topic management & Toba/tobatoba & not found \\
\hline $\mathbf{3}$ & Gee & Elaborative & Gee & not found \\
\hline $\mathbf{4}$ & Hai Allah & Topic management & Hai Allah & not found \\
\hline $\mathbf{5}$ & Take my word/for it & Elaborative & Take my word/with it & Elaborative \\
\hline $\mathbf{6}$ & Allah is merciful & Topic management & Allah is merciful & not found \\
\hline $\mathbf{7}$ & Mashallah & Topic management & Mashallah & not found \\
\hline $\mathbf{8}$ & May /Allah forgive me & Elaborative & May/ Allah forgive me & not found \\
\hline $\mathbf{9}$ & Inshallah & Elaborative & Inshallah & not found \\
\hline $\mathbf{1 0}$ & Allah/God be praised & Topic management & Allah/God be praised & (1 BNC) \\
\hline $\mathbf{1 1}$ & by the grace of Allah & Topic management & by the grace of Allah & not found \\
\hline $\mathbf{1 2}$ & Allah knows & $\begin{array}{l}\text { Inferential, Elaborative, } \\
\text { management }\end{array}$ & Allah knows God/I swear & not found \\
\hline
\end{tabular}

PE has its distinctive features that help it to be recognized it as a non-native variety (Noor at el, 2015). It contains nativised features due to acculturation and language contact situation. The above-mentioned table validates the phenomenon. PE fiction writers extensively use DMs influenced by Pakistani culture, for instance, 01 to 04 clearly indicate the influence of Urdu on PE which shares the status of official language of Pakistan with English (ibid). The expression Hai Hai (1) is extensively used in both languages respectively. It is mostly pertinent to females who express their feeling of expression of sorrow, surprise, fear, and astonishment. It is multifunctional in its context-based use and enhances the emotional content of the discourse to which it is attached, so that; this is placed in the category of topic management. It is used to adhere to the topic of discussion in discourse whether spoken or written. Similarly, DM (2) toba/toba toba expresses the regret on the part of the speaker. It is literally used for asking for forgiveness from the Almighty (Allah) but at discourse level, it employs a continuity to the discourse segments. Similarly, it is also used to reduce the effect of an ironic statement as presented in 2c. That is why; it falls in the category of topic management as it strictly correlates the topic to the succeeding segment of the discourse. Similarly, (3) Gee is an Urdu $\mathrm{DM}$ also present in PE which is used to initiate the topic and turn taking. It performs the function of and and/or so, so that functions as elaborative DM. It is also used in Indian English 
UNIVERSITY OF CHITRAL JOURNAL OF LINGUISTICS AND LITERATURE

VOL. 5 | ISSUE II | JULY - DEC | 2021

ISSN (E): 2663-1512, ISSN (P): 2617-3611

https://doi.org/10.33195/j1l.v5iII.297

(Valentine, 1991). Moreover, (4) Hai Allah is alternatively used as Hai Hai, such as for expressing worry, surprise, and regret performs functions of topic management for the adherence to the topic.

Instance (5) is an interesting example of a commonly varied feature of non-native varieties that is variation in the use of preposition. In PE, it is used as take my word for it whereas, in British Standard English (BSE) it is used as take my word with it. It is used for the assurance of S2 with S1, say, falls into the category of elaborative DM same as its BSE equivalent.

It is worth noting that nativised DMs ahead are mostly religious based that high point the strong reflection of culture and language that are of no exception. The examples of nativised DMs onwards are specifically related to religious expressions translated into English. However, they are not specifically used to convey purely religious meaning rather they are integrated as culturally specific DMs in language in order to lubricate and cohere the discourse. Mahmood (2009) well cites Baumgardner (1993) saying that for a complete understanding of PE newspaper, one must have awareness of Urdu language and Islamic culture.

The DMs (6) Allah is merciful and (7) Mashallah function as topic management DMs which express gratitude, praise, and appreciation with respect to the topic under discussion. Moreover, (8) May/ Allah forgive me and (9) Inshallah indicate the relationship between S1 and S2 with assigning coherence to discourse and function as elaborative DMs. Furthermore, (10) Allah be praised and (11) by the grace of Allah are used to express the gratitude in relation to the topic, so as come into the category of topic management DMs. The last DM of the nativised category is (12) Allah knows which performs multiple functions which is, by definition, a significant trait of DMs (Schiffrin, 1987). It posits relation between S2 and S1 performing elaborative function through a parallel sentence meaning exhibited in (12a) as explained by Fraser (2005) S1+DM+S2. It also postulates result of S1 in S2 as inferential DM presented in (12b) and it also manages the topic of discourse as used in (12c). It is worth noting that they add nothing to the propositional value of the sentences to which they are attached but their core meaning is negotiated by the context in which they occur or belong to. 
UNIVERSITY OF CHITRAL JOURNAL OF LINGUISTICS AND LITERATURE

VOL. 5 | ISSUE II | JULY - DEC | 2021

ISSN (E): 2663-1512, ISSN (P): 2617-3611

https://doi.org/10.33195/j1l.v5iII.297

It is also worthy to notice that all the nativised DMs are not found except single occurrence of (10) in BNC 100 million words corpus. The phenomenon supports the view of Akande (2009) that variation can be identified on the basis of region-specific DMs. Here, totally distinct use of above-mentioned DMs highpoints nativisation of English in Pakistan. Beside them, variation in the function of DMs between the native and non-native varieties (SBE and PE) is also present. The subsection below discusses the variant use of DMs in PE as compared to BSE.

\subsection{Variation in Use of DMs in PE and SBE}

Non-native varieties of English exhibit distinguishing features and different aspects of language and discourse strategies are one of them (Valentine, 1991). Answering the second research question, the study finds variation in the functional usage of DMs in written discourse which is a neglecting area of available literature. The Table-02 enlists eleven DMs with their variant use in both varieties.

Table-02: Variation in Use

\begin{tabular}{lllll}
\hline $\mathbf{S} \#$ & DMs in PENC & Use in PENC & DMs in BNC & Use in BNC \\
\hline $\mathbf{1}$ & But & Elaborative, Contrastive, Topic management & But & Contrastive, Inferential \\
\hline $\mathbf{2}$ & Or & Elaborative, Contrastive, & Or & Contrastive \\
\hline $\mathbf{3}$ & Mostly & Elaborative, Topic management & Mostly & Elaborative \\
\hline $\mathbf{4}$ & So now & Elaborative & So now & Inferential \\
\hline $\mathbf{5}$ & of course & Inferential, elaborative & of course & Inferential \\
\hline $\mathbf{6}$ & you know & Elaborative, Topic management, Inferential & you know & Elaborative, Topic management \\
\hline $\mathbf{8}$ & I think & Elaborative, Inferential, Topic management & I think & Topicmanagement, Elaborative \\
\hline $\mathbf{9}$ & Nothing else & Elaborative & nothing else & NOT USED AS DM \\
\hline $\mathbf{1 0}$ & Perhaps & Elaborative, Inferential & perhaps & Inferential \\
\hline
\end{tabular}

DMs in this section are commonly used in both varieties but there is found variation of varied degrees according to the functions they perform. The first instance of the abovementioned table (\#02) is a frequently used DM, but. It is extensively researched marker in most of the studies related to DMs (Muller, 2005). Apparently, it falls in the category of contrastive DMs but as mentioned in the review of literature, they are categorized according to the functions they perform within discourse segments. Interestingly, in PE, it is used for persuasive meaning as exemplified in (1a) based on which, elaborative function is also devoted 
to it. Furthermore, it also lubricates topic change strategy in the discourse as exhibited in (1c). That is why, it presents a variation in the function with SBE here, because the other two functions of but are found common while analyzing in both corpora.

The second DM in this table (02) is or which is again classified as a contrastive DM in most of the previous studies. In the example (2a) it functions as a contrastive DM while relating two opposing segments. It (or) is considered as transparent due to its semantic transparency. But the study responses to the claim of Ariel (1994) due to the multiplicity of function that is performed by or and by but (as mentioned earlier). In (2b), in which or employs the meaning of and, and is functioning as elaborative DM since it makes a quasi- parallel relation between the two segments $\mathrm{S} 2$ and $\mathrm{S} 1$ and imparts variation from its native counterpart use.

Similarly, (03) mostly also presents a variation in functioning in both varieties. In (3a) and (3b) it is employing elaborative function as in SBE whereas, in (3c-3f) it offers a relation of $\mathrm{S} 2$ back to $\mathrm{S} 1$ for managing the topic. Here, one more point is to be noticed that in SBE, mostly employs a low degree of possibility and means as almost but in PE it shows a high degree of possibility and capability (e.g. in 3f), giving the meaning of mainly. In the same line, the next entry of the above table (4a) so now depicts its common inferential function through imparting a result of $\mathrm{S} 1$ in $\mathrm{S} 2$. However, in (4b) it exemplifies the variant function of elaborative DM by making a parallel relationship between S1 and S2 $(\mathrm{S} 1+\mathrm{DM}+\mathrm{S} 2)$. Here, another point is to be highlighted with reference to Fraser (2015) concept of combining DMs which is said to be a less researched area. He analyses the combinations of contrastive and inferential DMs and intermixing of these two types and not discusses combining of inferential and elaborative DMs. This example (4) exhibits the combination of inferential and elaborative markers; so, and again respectively which also adds the combination to the Fraser's (2015) findings.

Furthermore, (05) of course displays variation in function in BSE and it is classified in the category of inferential DM by Lahuerta (2004), whereas in PE it performs dual functions, such as, in (5a) and (5b). In both instances, it makes a relationship between S2 and S1 and performs as elaborative DM. Moreover, in (5c) it employs an inferential function related to its literal meaning. PE writers and speakers use is as an additional part to grab the attention of 
UNIVERSITY OF CHITRAL JOURNAL OF LINGUISTICS AND LITERATURE

VOL. 5 | ISSUE II | JULY - DEC | 2021

ISSN (E): 2663-1512, ISSN (P): 2617-3611

https://doi.org/10.33195/j1l.v5iII.297

reader and listener and sometimes, it is deliberately used for the emphasis. Another social function that is imparted by the DM is to show solidarity between the discourse participants.

Additionally, (06) you know is another example of variation regarding function of DM. It is extensively researched DM (Jabeen at el, 2011) and said to be responsible for multiple functions (Jucker, 1993). Müller (2005) also discusses it and considers it as transparent DM and accepts its multiplicity of function. Here, you know puts forth inferential function while presenting S2 as a reason of S1 in (6a). Furthermore, in (6b) and (6c), it attains elaborative function through linking between S1 and S2. On the other hand, in (6d) it realizes the function of topic management while attaching S2 to S1. Here, inferential function posits variation as it is not observed in BSE.

Likewise, the next DM (07) I think is another largely visited DM by the researchers (Müller, 2005). It exhibits multiple functions and can be categorized in more than one category. In (7a) and (7b) it performs inferential function by assigning a reason to S1 by S2 which is not shared by BSE. Furthermore, in (7c) it is functioning as elaborative DM while smoothing the discourse connecting the S2 with S1. Additionally, in (7d), it is used as topic management $\mathrm{DM}$ as it links the $\mathrm{S} 2$ to the topic introduced in $\mathrm{S} 1$. The next (08) nothing else shows a strong variation because it is not used as DM in BSE whereas, it shows a couple of functions in PE. In (8a) it employs elaborative function of DMs with the help of establishing a link between S2 and S1 while on the other side; it functions as topic management DM in (8b). It relates the two segments to the topic introduced in S1.

In the example (09), perhaps shows variation in its use between BSE and PE. In (9a), it functions like BSE as elaborative DM and simply correlates S2 with S1 but in (9b) it functions as inferential DM by providing S2 as a deduction of S1. The last instance of this section is (10) Wah/Wah Wah which is an interesting DM. It is principally, used in Urdu and PE for the expression of happiness, appreciation, and joy whereas in BSE, it is said to be a cry and expresses sorrow. Literally, it is related to the change in the notes of electronic musical instruments. But in PE, it is used as a DM performing the function of topic management in (10a-10c). Contrary to that, in BSE it imparts elaborative function of DM. 
UNIVERSITY OF CHITRAL JOURNAL OF LINGUISTICS AND LITERATURE

VOL. 5 | ISSUE II | JULY - DEC | 2021

ISSN (E): 2663-1512, ISSN (P): 2617-3611

https://doi.org/10.33195/j1l.v5iII.297

This section presented a detailed description of variation found with respect to the functions performed by DMs. The next sub-section discusses variation in the positioning of DMs in sentences.

\subsection{Variation in the Position of DMs}

DMs provide semantic relationship to discourse segments. According to Fraser (2015), they typically occur at the beginning of S2 to cohere it with S1. But this is not always strictly followed. Brinton (1996) endorses the use of DMs at sentence middle and final positions. DMs in PE occur at all the three positions. It is validated by the study of spoken PE by Jabeen at el (2011). The Table-03 highpoints the instances of variant use of DMs in PE as compared to SBE.

\begin{tabular}{lllll}
\hline \multicolumn{2}{l}{ Table-03: Variations in Positioning } & \\
\hline $\mathbf{S}$ \# & DMs in PENC & Position in PENC & $\begin{array}{l}\text { DMs in } \\
\text { BNC }\end{array}$ & Position in BNC \\
\hline $\mathbf{1}$ & But & $\begin{array}{l}\text { Opening paragraph } \\
\text { (Global coherence) }\end{array}$ & But & $\begin{array}{l}\text { Not opening paragraph (Category: fic, } \\
\text { drama, classroom) }\end{array}$ \\
\hline $\mathbf{2}$ & Nothing else & Phrase stands alone & $\begin{array}{l}\text { Nothing } \\
\text { else }\end{array}$ & $\begin{array}{l}\text { Never stands alone (only once as: nothing } \\
\text { else happened) ( Category: fic, drama) }\end{array}$ \\
\hline $\mathbf{3}$ & Or & $\begin{array}{l}\text { Opening paragraph } \\
\text { (Global coherence) }\end{array}$ & Or & $\begin{array}{l}\text { Sentence initial but not opening paragraph } \\
\text { (no paragraph linkage) }\end{array}$ \\
\hline $\mathbf{5}$ & that is why & $\begin{array}{l}\text { Sentence initial and } \\
\text { between the sentence }\end{array}$ & That is why & Sentence initial \\
\hline
\end{tabular}

To analyze variation in the use of DMs contains their positioning as well because it varies from language to language and, here, from variety to variety. The first instance (01) but is used in the sentence initial position while opening a new paragraph. This phenomenon is termed as global coherence by Fraser (1999) in which DMs relate S2 with a prior discourse. In BNC but is not found as opening a new paragraph during the analysis of first hundred occurrences. The analysed excerpts were from the genera of fiction and drama in BNC.

The example (1a) shows a constant use of but at the initial position of the two consecutive paragraphs. In first case, it functions as inferential DM representing S2 because of S1 whereas, in second case, it is performing the function of elaborative DM linking the two segments of discourse. Similarly, in (1b) it opens the paragraph and functions as contrastive DM. The next example (02) nothing else explicates an interesting position totally variant with respect to $\mathrm{BNC}$ occurrences analysis consisting of the genera of fiction and drama. It is present 
UNIVERSITY OF CHITRAL JOURNAL OF LINGUISTICS AND LITERATURE

VOL. 5 | ISSUE II | JULY - DEC | 2021

https://doi.org/10.33195/j1l.v5iII.297

as standalone phrase in PE which has no match in BSE. In both examples (2a) and (2b) it functions as elaborative DM facilitating a link between $\mathrm{S} 2$ and $\mathrm{S} 1$ based on $\mathrm{S} 1+\mathrm{DM}+\mathrm{S} 2$ formula.

The upcoming DM (03) or is again, used at the paragraph initial position which is not found in BNC. Though the sentence initial position is followed by the DM in BNC, yet it not occurred as opening paragraph. The example (3a) supports the claim where it is functioning as topic management DM. It relates two distinct scenes to employ coherent to the topic of the description within discourse segments. Moreover, (04) that is why exhibits another variation in the position as it is found at sentence initial position in BSE whereas it is found in sentence medial position as illustrated in (4a) and (4b). In both cases, it is used as inferential DM since it relates the resultant discourse segment 2 to the $S 1$.

Finally, the last DM (05) mostly is used at rest of the three positions: S initial, S medial and $\mathrm{S}$ final in PE whereas it lacks this trait because in $\mathrm{BNC}$, it is found only at $\mathrm{S}$ initial position.

The categorization of DMs according to Fraser (1999) typology is displayed in the Table-04.

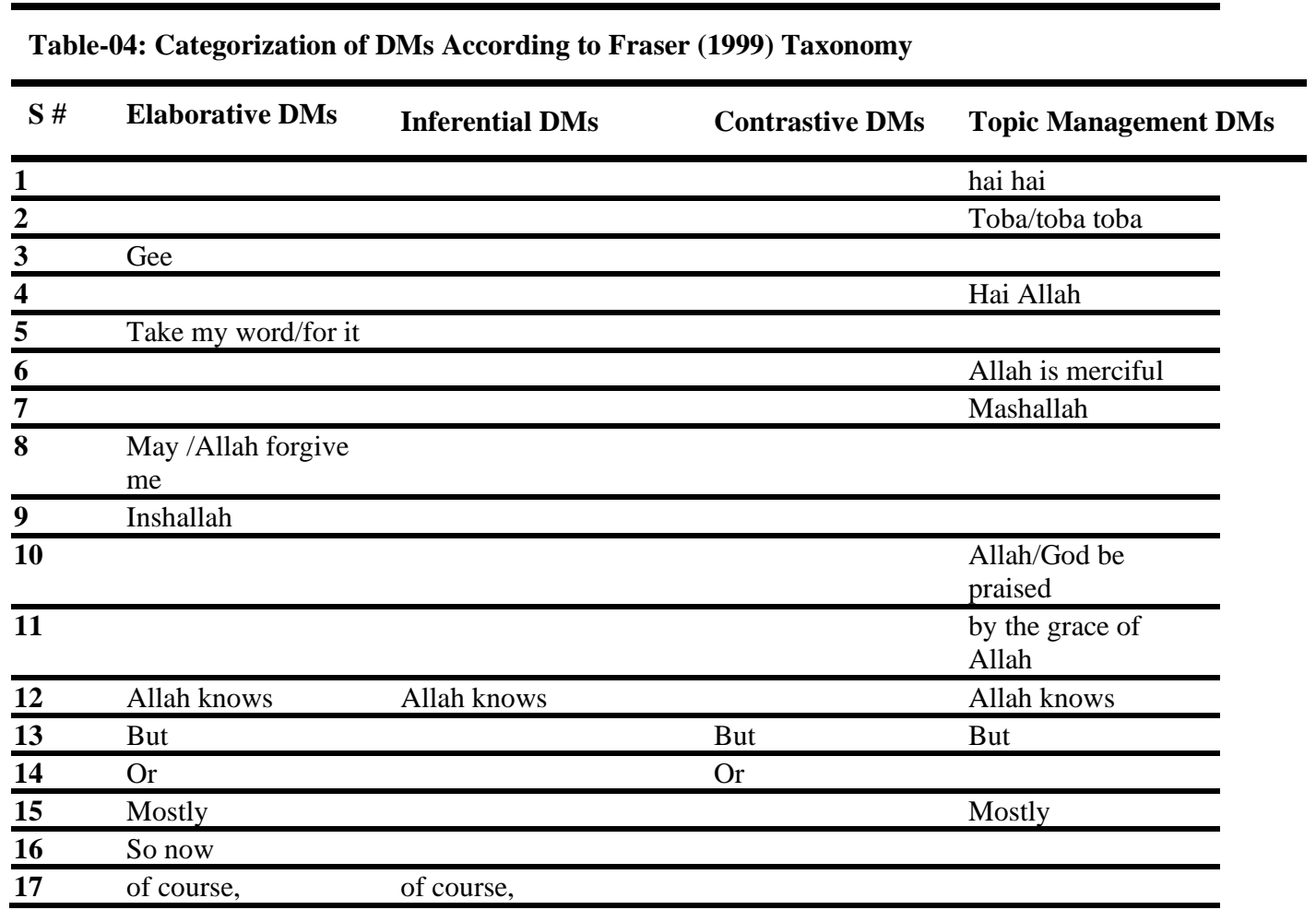


UNIVERSITY OF CHITRAL JOURNAL OF LINGUISTICS AND LITERATURE

VOL. 5 | ISSUE II | JULY - DEC | 2021

ISSN (E): 2663-1512, ISSN (P): 2617-3611

https://doi.org/10.33195/j1l.v5iII.297

\begin{tabular}{llll}
\hline $\mathbf{1 8}$ & you know & you know & you know \\
\hline $\mathbf{1 9}$ & I think & I think & I think \\
\hline $\mathbf{2 0}$ & Nothing else & & \\
\hline $\mathbf{2 1}$ & perhaps & Perhaps & wah/wah wah \\
\hline $\mathbf{2 2}$ & & & \\
\hline $\mathbf{2 3}$ & & That is why & \\
\hline & The & analyzed & DMs \\
\end{tabular}

The analyzed DMs are listed above according to their respective function-based categories. The data analysis supports the multiplicity of the functions of DMs. After the analysis, there are fourteen DMs in the category of elaborative DMs whereas, in the category of inferential DMs there are six DMs enlisted. As far as the category of contrastive DMs is concerned, only two DMs are found. Furthermore, several thirteen DMs are categorized as topic Management DMs. The subsequent section concludes the entire study and discussion.

\section{CONCLUSION}

It is evident that PE written discourse, with special reference to the genre of fiction, exhibits the phenomena of nativisation and variation of DMs use. The study highlights culturally specific DMs which are used in written discourse. This genre is not comprehensively studied by the previous studies due to the reason that DMs are considered as an active part of spoken discourse and are less applied in Written (carefully prepared) discourse. The current study contributes to the existing body of knowledge relating to DMs apart from typical classroom discussions and purely corpus based quantitative analyses. It brings forth twelve nativised DMs and ten variant DMs, whereas variation in the position of DMs is analysed through five DMs. It is significant to state that nativised DMs profusely perform topic management function. Furthermore, it is worth noting that though most of them are translations of religious particles, yet they have nothing to do with their literal meaning. It supports the notion of negotiating the context-based meaning through DMs. It also strengthens the multiplicity of functioning of DMs the notion held by Schiffrin (1987) and Müller (2005). The study addresses the claim of Ariel (1994) who considered the DM or as a transparent one and exemplifies its multiple functions. Furthermore, it responses to the study of Lahuerta (2004) that puts of course into the category of inferential DMs, however, in PE it is found performing the functions of elaborative as well as inferential DM. Moreover, it adds to the study of combining DMs by Fraser (2015) through the analysis of combination of inferential and 
UNIVERSITY OF CHITRAL JOURNAL OF LINGUISTICS AND LITERATURE

VOL. 5 | ISSUE II | JULY - DEC | 2021

https://doi.org/10.33195/j1l.v5iII.297

elaborative DMs. Finally, it provides a foundational ground with respect to the research aspects of non-native varieties of English and opens a debate on the subject matter with reference to the future studies with multiple genres.

\section{IMPLICATIONS}

Though, the use of DMs by males and females was out of the scope of the study, yet it is suggested to the future researchers to search for the different use of DMs with reference to gender as done by Yeganeh and Ghoreyshi (2015) who highlighted discrepancy among the male and female users. Moreover, similar studies are needed in other genres to validate the findings of nativised/varied DMs.

\section{REFRENCES}

Akande, A. T. (2009). Discourse markers in the spontaneous speech of Nigerian university graduates. Lagos Papers in English Studies, 4, 28-37.

Ali. E. A. M., and Mahadin. R. S. (2016). The Use of Discourse Markers in Written Discourse by Students of English at the University of Jordan. International Journal of Humanities and Social Science ,6(3), 23-35.

Alami, M. (2015). Pragmatic functions of discourse markers: A review of related literature. International Journal on Studies in English Language and Literature, 3(3), $1-10$.

Ariel, M. (1994). Pragmatic operators. The Encyclopaedia of Language and Linguistics. Ed. R. E. Asher. Oxford: Pergamon P. (6): 3250-53.

Baumgardner, R. J. (1993). The English Language in Pakistan. Karachi: Oxford University Press.

Brinton, L. J. (1990). The development of discourse markers in English. Historical linguistics and philology, 46, 45.

Brinton, L. J. (1996). Pragmatic markers in English: Grammaticalization and discourse functions (19). Walter de Gruyter.

Castro, C. M.C. (2009). The Use and Functions of Discourse Markers in EFL Classroom Interaction. Profile. 11(1).57-77. eISSN 2256-5760. 
UNIVERSITY OF CHITRAL JOURNAL OF LINGUISTICS AND LITERATURE

VOL. 5 | ISSUE II | JULY - DEC | 2021

ISSN (E): 2663-1512, ISSN (P): 2617-3611

https://doi.org/10.33195/j1l.v5iII.297

Crystal, D. (2012). English as a global language. Cambridge university press.

Fraser, B. (1996). Pragmatic markers. Pragmatics. Quarterly Publication of the International Pragmatics Association (IPrA), 6(2), 167-190.

Fraser, (1998). Contrastive Discourse Markers in English. In: Jucker \& Ziv(eds): Discourse Markers: John Benjamin’s Publishing Company.301 - 326.

Fraser. B. (1999). What Are Discourse Markers. Journal of Pragmatics.31. 931-952.

Fraser, B. (2015). The combining of Discourse Markers -- A beginning. Journal of Pragmatics http://dx.doi.org/10.1016/j.pragma.2015.06.007.

Feng, L. (2010). Discourse Markers in English Writing. The Journal of International Social Research. 3(11). Retrieved from:http://www.sosyalarastirmalar.com/cilt3/sayi 11pdf/feng_li.pdf, 15/11/2017.

Fuller, J. M. (2003). The influence of speaker roles on discourse marker use. Journal of Pragmatics, 35(1), 23-45.

Fung, L., and Carter, R. (2007). Discourse markers and spoken English: Native and learner use in pedagogic settings. Applied linguistics, 28(3), 410-439.

Gholami, J., Mosalli, Z., \& Nikou, S. B. (2012). Lexical complexity and discourse markers in soft and hard science articles. World Applied Sciences Journal, 17(3), 368-374.

Guo, F. (2015). A review of discourse markers from the functional perspective. Journal of Arts and Humanities, 4(4), 69.

Halliday, M., and Hasan, R. (1976). Cohesion in English. London: Longman.

Hansen, M. B. M. (2006). A dynamic polysemy approach to the lexical semantics of discourse markers (with an exemplary analysis of French toujours). Approaches to discourse particles, 21-41.

Hauge, K. R. (2014). Found in translation-discourse markers out of the blue. Oslo Studies in Language, 6(1).

Hussein, M. (2007). Two accounts of discourse markers in English. Retrieved June 06, 2011.

Jabeen, F,, Rai, M, A,. and Arif, S. (2011). A Corpus Based Study of Discourse Markers in Pakistani and British Speech. International Journal of Language Studies. 5(4). 69-86. 
UNIVERSITY OF CHITRAL JOURNAL OF LINGUISTICS AND LITERATURE

VOL. 5 | ISSUE II | JULY - DEC | 2021

\section{https://doi.org/10.33195/jll.v5iII.297}

Jalilfar, A. (2008). Discourse markers in composition writings: The case of Iranian learner of English as a foreign language. English Language Teaching, 1(2), 114-122.

Jucker AH. (1993). The discourse marker 'well': a relevance theoretical account. Journal of Pragmatics 19, 435-452.

Kachru, B. B. (1983). The indianization of English: the English language in India. Oxford University Press.

Kalajahi, S., Abdullah, A. N. B., and Baki, R. (2012). Constructing an organized and coherent text: How discourse markers are viewed by Iranian post-graduate students. International Journal of Humanities and Social Science, 2(9), 196-202.

Kammensjo, H. (2005). Discourse Connectives in Arabic Lecturing Monologue. Acta Universitatis Gothoburgensis. Sweden. ISSN 1404-3556, ISBN 91-7346-541-0.

Kaveifard, E., and Allami, H. (2011). Inferential Discourse Markers in Discussion Section of Psychology Research Articles across English and Persian. Theory \& Practice in Language Studies, 1(12).

Lahuerta M , A. C. (2004). Discourse markers in the expository writing of Spanish university students. Ibérica, (8).

Llurda, E. (2004). Non-native-speaker teachers and English as an International Language. International Journal of Applied Linguistics, 14(3), 314-323.

Mahmood, M, A. (2009). A Corpus Based Analysis of Pakistani English (Dissertation for Doctoral Degree). Submitted to Bahauddin Zakariya University Multan, Pakistan.

Müller, S. (2005). Discourse markers in native and non-native English discourse, (138). John Benjamins Publishing.

Noor M, Anwar B, Kazemian B, Mangrio RA, Muhabat F. (2015). Distinctiveness of Pakistani English in Online Travel Guides of Pakistan. Inter. J. Eng. Lit. Cult. 3(5): 150-159.

Redeker, G.(1991). Review Article: Linguistics Markers of Discourse Structure. Linguistics. 29 (6).1139-1172.

Schiffrin, D. (1987). Discourse Markers. Cambridge: Cambridge University Press. 
UNIVERSITY OF CHITRAL JOURNAL OF LINGUISTICS AND LITERATURE

VOL. 5 | ISSUE II | JULY - DEC | 2021

Sharndama, E. C., and Yakubu, S. (2013). An analysis of discourse markers in academic report writing: pedagogical implications. International Journal of Academic Research and Reflection, 1(3), 15-24.

Siddique, A. R., Mahmood, M. A., and Iqbal, J. (2017). Metadiscourse Analysis of Pakistani English Newspaper Editorials: A Corpus-Based Study. International Journal of English Linguistics, 8(1), 146.

Tree, J. E. F., and Schrock, J. C. (1999). Discourse markers in spontaneous speech: Oh what a difference an oh makes. Journal of Memory and Language, 40(2), 280-295.

Tree, J. E. F., and Schrock, J. C. (2002). Basic meanings of you know and I mean. Journal of Pragmatics, 34(6), 727-747.

Trillo, J. R. (2002). The pragmatic fossilization of discourse markers in non-native speakers of English. Journal of pragmatics, 34(6), 769-784.

Valentine, T. M. (1991). Getting the message across: discourse markers in Indian English. World Englishes, 10(3), 325-334.

Yang, S. (2011). Investigating discourse markers in pedagogical settings: a literature review. Annual Review of Education, Communication \& Language Sciences, 8.

Yeganeh, M. T., and Ghoreyshi, S. M. (2015). Exploring Gender Differences in the use of Discourse Markers in Iranian Academic Research Articles. Procedia-Social and Behavioral Sciences, 192, 684-689. 


\section{APPENDIXES}

\section{NATIVISED DMs:}

1a) he replied and caught hold of her.'Hai hai, what has happened to you? It's so cold. Leave me'

1b) From the came the voice of Begam Jamal moaning and growling:'Hai, hai I am dying.

2a) Probably.' 'God forbid! Toba!' muttered Zaitoon, scandalised by the revelation.

2b )she wraps herself back in and bounces down among us. 'Toba, toba!' she says, and touching the tips of her ears in quick succession saying

2c) Miriam laughed. Toba, toba! Have you no shame?

3a) Balancing his slender shanks against the seat, he spread his hands as if embracing all tho passengers with his affectionate gesture. 'Gee, lady," he said to Feroza with such rapture that he appeared to be lit up irom within.

3b) "Gee " he said, bowing his head very low, 'I will bring my old hands to give beauty to your house."

4a) she screams: 'You'll kill me! Hai Allah... Y'all will kill me!'

4b) struck their breasts and sobbed, 'Hai Bhagwan! Hai Bhagwan! and, 'Hai Allah! Hai Allah!' The fireman once again climbed the ladder.

5a) I shall get you a charm which will act like -magic. Take my word...'

5b) You have to take my word for it

5c) You take my word for it, Umeed; you will never achieve anything... especially not love.

6a) we grumble and complain about what we do not have and we wanted. Allah is merciful; $\mathrm{He}$ is benevolent that He continues to shower His bounties on us.

6b) We pray for your brother, 'Don't fret, he will be free. Allah is merciful!'

7a) I enjoyed your story very much._Mashallah_, God has granted you a special talent.

7b) Sour apples,” I said. “_Mashallah_, you're just about the smartest little guy I've ever met, Sohrab jan."

8a) Do any of the other servants know anything?`May Allah forgive me, sir! Why would I let anyone else know? I haven't told a soul.' 
UNIVERSITY OF CHITRAL JOURNAL OF LINGUISTICS AND LITERATURE

VOL. 5 | ISSUE II | JULY - DEC | 2021

8b) There were a lot of reasons why I went to Hazarajat to find Hassan in 1986. The biggest one, Allah forgive me, was that I was lonely.

8c) Smile for me. Please."Hassan did and the old woman wept. "You smiled coming out of me, did anyone ever tell you? And I wouldn't even hold you. Allah forgive me, I wouldn't even hold you."

9a) Some day,_Inshallah_, you will be a great writer," Hassan said.

9b) You would tell me, nay?_Inshallah_, you would tell me if some thing had happened? He had stressed.

10a) the word =your ${ }^{6}$ in stead of saying $=$ mine $^{6}$. =Yes, Allah be praised. It's a very wellplaced match

10b) The men were Prince eereK. gel hot $\bullet P \bullet$ Piessly above his head and announced, 'God be praised, but it's Kamaruddin, stretched out on the cushions, raised his arms

11a) "It's all His blessing. I went on a ride in one of ours and my old bones were aching for days. You, by the grace of Allah, are still a young man."

11b) "With your blessings I have introduced the new laws in Pakistan and by the grace of Allah hundreds of sinners have already been convicted

12a) 'It's over now. You might as well help me change it. Allah knows how I'll explain this.

12b) 'What is the Major carrying?' Sakhi's voice was uncertain and tight. 'Allah knows! He has strange hobbies. He collects things: stones and chunks of wood...'

12c) Sharbat Khan cautions Ayah: 'These are bad times - Allah knows what's in store.

\section{VARIATION IN USE:}

1a) You have heard enough for today,. But aunt, do tell us the story of the king who have turned..

1b) 'the minarets .point to heaven, indicating, as it were that God is al high and one....

But the. City of Delhi, built hundreds of years ago, fought for,

1c) Disappointed, Asghar made to go. But Chanbeli said: 'But your sister-in-law is there.

2a) He looks up at the sky Time was the Milky Way stretched out from one end of the sky to the other, a bright light of incandescence, broadening out or narrowing to a straight line

2b) ,heat becomes oppressive or shoots through the /body like pain; 
2c) Give in the name of God, mother, and may thy children live long.

Or a belated flower vendor sells jasmines in a sing-song voice putting one hand on his ear...

3a) The time passed mostly between eating, talking, cooking, sewing, or doing nothing.

3b) Mostly the children were happy and played or quarreled among themselves.

3c) He used to hang out with them mostly,

3d) People stare at you, they grunt and sigh women mostly.

3e) A mostly male mob is gathered outside the gate, hoping to get in. Its summertime, after all, and parties are few and far between.

3f) But mostly I'm Aurangzeb. And regardless of what you've heard, I'm not a bad guy.

4a) It reduces you to the bomb. Every atom of you. So now I have to find something different to want, Elizabeth.

4b) =And do you know how selfish you are gradually becoming?' Waseem replied likewise. Imama did not mind it. =So now you know how selfish I am?'

5a) Shams, of course, got up late, went to the office-he was employed in a Government officecame back at five

5b) I speak English,' the boy said, his tone offended. 'And Japanese and German.' For the first time in months he had reason to boast, and that made boasting necessary. 'And Urdu, of course. Pashto, also. What do you speak? geographically, of course, it was perhaps as remote a place as could be found on the planet,

5c) So of course you can be American.

6a) 'What happens when a dust-storm comes? Came a child's voice From the semi-darkness; 'You know our elders say when a dust-storm blows it means the jinn's are going to celebrate a marriage'(inferential)

6b) The matter concerns him, you know.' 'What you are saying is all right (elaborative)

6c) They were the clothes which are sent to the bride from the bridegroom's side. You know, at my marriage...' someone would recall the past (elaborative)

6d) 'They have invented remarkable machines, you know," said the kababi as he pulled at the hookah, 'which can conceal thousand of soldiers and carry them right into the midst of the enemy without being seen] (topic management) 
7a) "Spare me," I think, "I didn't invent the bloody technology that makes foam mattresses." (inferential)

7b) She couldn't be more than twelve, I think, surprised. 'Why didn't you bring him earlier? (inferential)

7c) "Comrade, I think I've gone blind. I can't see anything. "I rub my own eyes and don't see anything (Elaborative)

7d) 'Do you find anyone more attractive than me?' 'Yes,' I say, 'I think I found Masseur more attractive...' I surprise myself. (topic management)

8a) Is that all Cathy has told you about her past? Nothing else?' Asim kept his voice noncommittal. 'That is all she has told me. (elaborative)

8b)' We're just here to evacuate you: hands, feet and heads. Nothing else. We've told you why we're here; the rest is up to you.' Topic Management

9a) But still he had worked on, to cheat Time, perhaps, to avoid the feeling of dependence even though on his sons. elaborative

9b) Why had he been in love with her, he thought, and why had he become indifferent to her? She had loved him and adored him, perhaps. Why did he not feel anything for her? Inferential

10a) the greater his power. 'Wah, Allah!' shouts Ice-Candy Man. 'There is no limit to your munificence!

10b) And the villagers, as if they are at a debate where their chaudhry's wit is scoring points, nod their heads and say: 'Wah! Wah! Well said!

10c) What a joyous day that was!" he said. "An end to the killing! Wah wah!

\section{VARIATION IN THE POSITION OF DMs:}

1a) He is oblivion of the other stars, oblivious of himself and of Mushtari Bai who comes near him dancing around, but he turns away, and interested in his own body in love with his own flesh and the movements of his own arms ....

But as slowly as it had come upon him the vision vanishes: and when he awakes he finds himself on his bed gazing at the Sky. But where is the Milky Way? He says to himself 
UNIVERSITY OF CHITRAL JOURNAL OF LINGUISTICS AND LITERATURE

VOL. 5 | ISSUE II | JULY - DEC | 2021

https://doi.org/10.33195/j1l.v5iII.297

It use to be here just over his head. Where has it gone?... Thinking the Milky Way he falls asleep.

But he awakes again. Or was it a continuation of the vision or the dream? He looks up at the sky

1b) .. shouting in the resonant tones :Buy the flower of Jasmine".

But the city lies indifferent or asleep, breathing heavily..

2a) intersect the streets and the city like the deep gutters which line them on either side, and grow narrower as you plunge into them giving a feeling of suffocation grid death, until they terminate at some house front or meet another net of by-lanes as insidious as in the wall 'at floor. Nothing else. As you en e through the vestibule you home into an inner courtyard.

2b) 'We're just here to evacuate you: hands, feet and heads. Nothing else. We've told you why we're here; the rest is up to you.'

3a) Give in the name of God, mother, and may thy children live long.

Or a belated flower vendor sells jasmines in a sing-song voice putting one hand on his ear...

4a) If that is why you called, I can remember us wrestling a bit. may be that is why he was so upset about the missing gun

4b) and had forced themselves upon India Perhaps that is why that unity of experience an arm which existed in Mir Nihal s youth, had vanished.

5a) Mostly the children were happy and played or quarreled among themselves.

5b) The time passed mostly between eating, talking, cooking, sewing, or doing nothing.

5c) He used to hang out with them mostly,

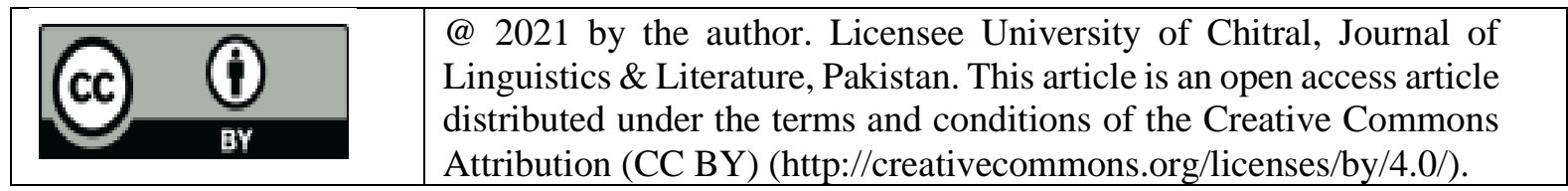

